\title{
Construction of Modular-Based Curriculum Framework for Medical English Teaching in China
}

\author{
Changyou Wang ${ }^{1}$, Haiyang Wang ${ }^{2} \&$ Xinhua Luan ${ }^{1}$ \\ ${ }^{1}$ School of Foreign Language, Yanbian University, Jilin Province, China \\ ${ }^{2}$ School of Electronics \& Information Engineering, Tianjin Polytechnic University, China \\ Correspondence: Changyou Wang, School of Foreign Language, Yanbian University, Jilin Province, China.
}

Received: September 29, 2020

Accepted: November 13, $2020 \quad$ Online Published: November 20, 2020

doi: $10.5539 /$ elt.v13n12p37

URL: https://doi.org/10.5539/elt.v13n12p37

\begin{abstract}
Current research on the medical English curriculum system is in an unsystematic state. According to the modular teaching theory and ESP classification, especially Hutchinson \& Waters's (1986) and Jordan's (1997) categories, three modules of medical English curriculum system are put forward for non-English speaking countries to cultivate their international medical students and strengthen their international cooperation. These modules are Medical Humanities English, Medical Occupational English and Medical Academic English. Each of the above modules is independent but related to the others in a sequential relationship. Offering modular medical courses not only provides a language platform for medical students to catch up with the pace of internationalization, but also accelerates the process to study the advanced medical technology through international communications.
\end{abstract}

Keywords: modular-based, curriculum framework, medical English, China

\section{Introduction}

In recent years, international communications in different fields has been increasing. The same is true in global health communications, especially after the outbreak of global public health diseases, such as Ebola, AIDS, SARS, H1N1, MERS, COVID-19. As a developing country, Chinese medical technology is less advanced compared with that in the developed countries. In order to catch up with them, the Chinese government introduced the following policies to call for cultivating applied international medical students: The National education reform and development of medium and long-term planning programs (2010-2020) (Ministry of Education of PRC, 2010), Opinions on speeding up the construction of high-level undergraduate education and comprehensively improving the ability of talent cultivation (Ministry of Education of PRC, 2018), On strengthening the collaboration between medicine and education to implement the Excellent Doctor Education Training Program 2.0 (Ministry of Education of PRC, 2018). One way to accelerate the cultivation of international medical students is to offer medical English courses. Medical English, which is a branch of English for Special Purpose (ESP), can provide an accurate language platform to engage in international communications, and to study the latest developments in medicine. Because of the significance of medical English courses, the objective of this paper is to discuss the contents of medical English teaching, that is, its curriculum framework. How is the current research status of the curriculum system now?

\section{Research Status of Medical English Curriculum System at Home and Abroad}

In some developed countries such as Britain and America, because English is their mother tongue, they mainly focus on medical terminology. For example, University of California, San Diego offers an intensive course on medical terminology that meets 15-20 hours per week for four consecutive weeks. Other countries, such as Britain, Australia and Canada, have almost the same practice (Ren, 2020). Countries whose native language is not English, such as Japan and South Korea, are also teaching medical English (Zhao, 2013). However, when searching for materials from the CNKI, we could find that only a few papers in China have discussed the medical English curriculum of the foreign countries. For instance, the medical English courses in Tokyo Medical University include both the elementary courses and the comprehensive courses. The former consists of lexicology and literature reading, and the latter is made up of medical terminology, clinical concepts, medical conversation and medical reading (Lv, 2008; Zhang \& Wang, 2012). When searching for materials from the other countries, we could find that the number of papers written in English about the same topic is limited. Meanwhile 
papers written in other languages are difficult to understand for a reader who only knows English and Chinese because of the language barriers. So little is known about the research status of medical English curriculum in foreign countries.

In China, according to the nature of Chinese universities, scholars have put forward some useful suggestions on the medical English curriculum, and those can be divided into two patterns. The first pattern is "English for General Purpose (EGP) + English for Medical Purpose (EMP)," which is held by most people, such as Wu and Feng (2014), Wang (2013), Zhang and Liu (2011), Shen, Gu and Shan (2014), Cui, Shi and Xu (2013), Zhao (2013), An and Zhang (2020). But this pattern is based on the overall curriculum framework of EGP instead of EMP. Meanwhile the contents of occupational English and academic English are somewhat mixed together in their research. The second pattern is "Academic English + Occupational English + Humanistic English" which was put forward by Cao (2016) for medical graduate students. At present, this is a relatively clear curriculum which provides some ideas for this study, but she did not discuss it in detail, and some questions still need further research.

Looking back at the research status about the topic, it is still in a fragmented state. So there is no widely recognized medical English curriculum system. That is why the idea of constructing a modular-based medical English curriculum framework is put forward to provide guidance for effective medical English teaching, and to eventually catch up with the advanced medical technology.

\section{Theories of Modular-Based Curriculum Framework for Medical English}

\subsection{Modular Teaching Theory}

The modular teaching method, which is based on skill training, was developed by the International Labor Organization in the early 1970s. The research and practice of a modular teaching method in China began in the 1990s and has achieved great results. In the field of education, modular theory combines knowledge with similar functions in one discipline into knowledge modules. These modules (or module groups) are relatively independent but logically related with each other (He, 2009). Modular teaching theory aims at quality-oriented education. In order to achieve that goal, the teaching contents are divided into different teaching modules according to different training objectives (Hua, Zheng, \& Zhao, 2014). Therefore, the teaching tasks and objectives of each module will be clearer and more concrete, and the students can easily master them one by one. Finally, their language ability will be improved.

\subsection{ESP Classification Theory}

ESP originated in the 1960s and has been widely used in many foreign countries and regions since the 1970s, including: Greece, France, Norway, Denmark, Italy, Finland, Germany, Sweden (Zhang, 2014), Japan, and the region of Taiwan (Zhao \& Zhang, 2014). The ESP research in China started in the late 1970s and has recently become a hot topic in EGP teaching reform. There are many categories of ESP, among which Hutchinson \& Waters' (1986) and Jordan's (1997) classifications are the most influential. Hutchinson \& Waters divided ESP into English for Occupational Purpose (EOP) and English for Academic Purpose (EAP). Its EAP was subdivided into English for Specific Academic Purpose (ESAP) and English for General Academic Purpose (EGAP) (Fig. 1). Jordan classified ESP into three types, and they were respectively: English for Science and Technology (EST), English for Business and Economics (EBE), and English for Social Science (ESS). Each of the above types was further subdivided into EAP and EOP (Fig. 2).

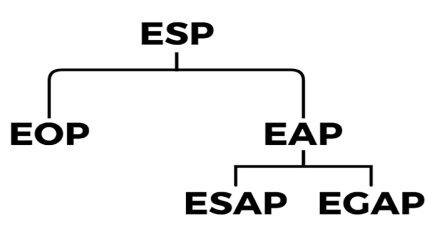

Figure 1. Hutchinson \& Waters's Classification (1986)

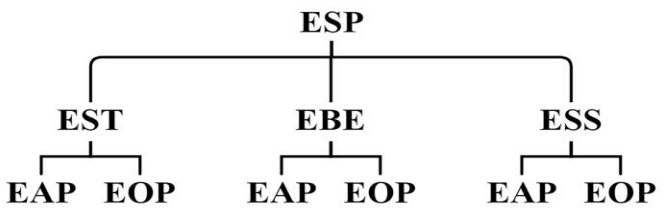

Figure 2. Jordan's Classification (1997)

The above theories of modular teaching and ESP classification provide the theoretical basis for the development of this paper.

\section{Framework of Modular-Based Curriculum for Medical English}

To reflect the humanistic and instrumental characteristics of the English language, we should consider the humanistic problems in the healthcare industry in China, especially the doctor-patient relationship. According to modular teaching theory, and Hutchinson \& Waters' (1986) and Jordan's (1997) ESP classification, three medical 
English modules are put forward. These modules are: Medical Humanities English (MHE), Medical Occupational English (MOE) which includes basic medicine and clinical medicine, and Medical Academic English (MAE) which includes English for Medical General Academic Purpose (EMGAP) and English for Medical Specific Academic Purpose (EMSAP) (Fig. 3). Medical Terminology English (MTE) is also an important part of this modular curriculum system, but it can be integrated into the relevant chapters of MOE.

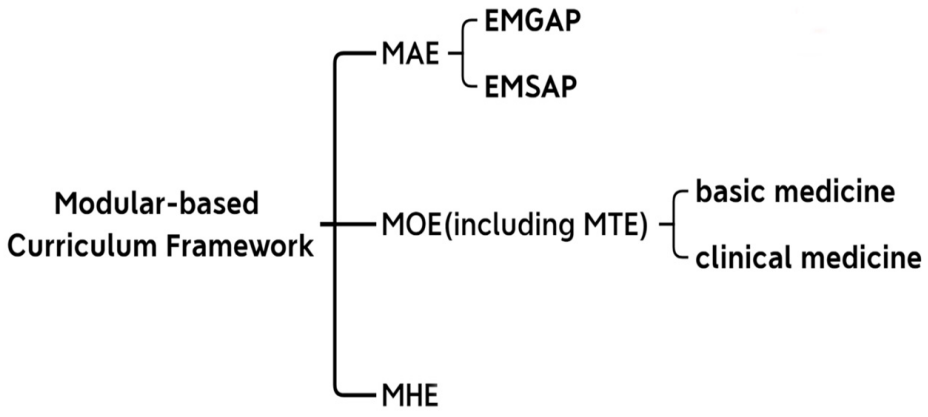

Figure 3. Modular-based Curriculum Framework

\subsection{Medical Humanities English (MHE)}

MHE helps shape students' values and medical ethics to foster a humanistic and professional spirit. The basic connotation of medical humanities is humanitarianism, i.e., the idea of public welfare and universal love. MHE involves less technical content, and it is the introductory course of the medical modular curriculum system.

The dictionary of new disciplines in soft science of medicine (Sun, 1992) categorized medical humanities as follows: medical history, medical introduction, future medicine, social medicine, psychological medicine, medical ethics, medical law, medical thinking and cognition, medical philosophy, medical methodology and medical logic. Each of the above categories contains more information. For example, social medicine includes: healthcare/nutrition, doctor-patient disputes, and public health. Medical ethics includes: surrogacy, organ transplantation, first aid, end-of-life care, the Hippocratic Oath, the Florence Nightingale Pledge, and euthanasia. In addition to the above categories, the following items should also be included because they have characteristics that fit the humanistic spirit: medical aesthetics, behavioral medicine, medical education system, and medical insurance system.

\subsection{Medical Occupational English (MOE)}

MOE helps learners to develop their communicative ability in a medical context according to their needs, and would include: the use of English in basic and clinical teaching, clinical home visits and ward rounds, doctor-patient dialogues, and case discussions. MOE covers a large amount of professional knowledge and medical terminology, so it is relatively difficult to learn and it is considered a "tough" course in the modular curriculum system.

The medicine major contains basic and clinical stages. So in basic medicine, the following items should be involved: the representative articles of the main courses, medical vocabulary, medical sentence patterns, and medical practical writing. In clinical medicine, the following items should be involved: the representative articles of the main courses, medical vocabulary, doctor-patient dialogues, case discussions, instructions for drug or instruments, ward rounds, medical images, and medical correspondence.

\subsection{Medical Academic English (MAE)}

MAE is taught to enable students to express medical academic thoughts in English. It commonly appears in journal articles, masters and doctoral theses, literature review, academic conference communication, academic speeches and so on (Long, 2011). MAE is based mainly on MOE, so it could follow the MOE course in the modular curriculum system.

Academic English is not a course, but a curriculum system. According to Hutchinson \& Waters' (1986) classification (EGAP \& ESAP), MAE should be subdivided into EMGAP and EMSAP due to a wide range of disciplines in medicine. EMGAP mainly emphasizes the general academic communicative abilities developed from the main courses in both basic and clinical medicine, including: delivering academic speeches (for example, TED Talks), recording and presiding over academic meetings, participating in academic discussions and expressing opinions, retrieving and reading literature, writing literature reviews and abstracts, avoiding plagiarism, and others. EMSAP mainly focuses on the specialized academic communicative skills gained from the main courses in both basic and clinical medicine, including: SCI writing, presentation of papers or 
experimental/case studies, international academic exchanges, case retrospective analysis, cooperation of academic teams, etc.

We should realize that medical English belongs to the field of linguistics. Therefore, the contents of each modular-based curriculum should not involve excessive medical professional knowledge, otherwise it will become like a medical course in English-speaking countries. Among the above modular courses, MHE is a transitional course which connects EGP and EMP, so as to avoid abrupt changes from EGP to EMP. MOE is the foundation of MAE because the medical terminology and sentence patterns in MOE form the basis to study MAE. Although the modular courses in medical English are relatively independent, they are interconnected in content and have a sequential relationship.

Notes: The main courses in basic medicine mentioned above include: human anatomy, histoembryology, physiology, biochemistry, and pathology. The main courses in clinical medicine include: diagnostics, surgery, internal medicine, obstetrics and gynecology, and pediatrics.

\section{Implementation of a Modular-Based Curriculum Framework for Medical English in China}

Higher Education in China can be classified into four different levels: research-oriented schools, teaching-oriented schools, research and teaching-oriented schools, and higher vocational colleges. The same is true for medical schools. Due to the mergers of colleges and universities in recent years, statistics show that the number of public medical undergraduate schools has decreased from 150 (Zhao, 2013) in 2013 to 77 in 2019 (Ministry of Education of PRC, 2019). In other words, nearly half of the public medical undergraduate schools have been merged into public universities. So, compared with the past there are fewer independent public medical schools and more medical colleges within a public university. The different school levels and their independence mean that the modular-based curriculum of medical English should be implemented according to their unique requirements.

\subsection{Independent Medical Schools: One School, One Policy}

The department responsible for teaching English in independent medical schools has relative autonomy about whether and when to offer medical English courses. However, due to the different levels of the schools, student fluency in English varies greatly. In order to strengthen the respective development of schools and actively serve the needs of students, different medical schools should determine their own teaching content and times to offer medical English courses. They could do this according to their training objectives, learners' needs and their English level, teacher resources and so on. For example, research-oriented schools mainly offer MOE and MAE courses, teaching-oriented schools mainly offer MHE and MOE courses, supplemented by MAE, and higher vocational colleges mainly offer EGP courses, supplemented by MOE and MHE. This provides independent medical schools the flexibility to best serve the students.

\subsection{Medical College within a University: One Major, One Policy}

In a merged university, the department responsible for teaching English usually creates the unified teaching content and teaching plan within the whole university. Regardless of the characteristics of each major, the teaching arrangement is almost the same. The uniformity of teaching arrangement, to some extent, weakens the relative autonomy of medical English teaching, and even prevents the development of medical English. In recent years, because the popularity of the medical majors could attract students with good grades, they can meet the basic requirements of the English curriculum earlier than students from other majors. Given that the total number of English class hours remains the same, it is possible to reduce the class hours for EGP and extend the time for EMP. With the urgent needs for EMP among medical schools, it is suggested to apply the "One Major, One Policy" concept to the Teaching Affairs Department, so that medical English courses can be offered appropriately in the merged universities.

\section{Conclusion}

In summary, according to the relevant theories mentioned above, the construction of a modular-based curriculum framework could clarify the meaning and mutual relations of various modular courses. The clear curriculum framework makes it easier to implement medical English teaching and achieve the corresponding goals. The implementation of "One School, One Policy" and "One Major, One Policy" would increase the students' humanistic consciousness, enlarge their professional knowledge, and improve their international communicative ability. Eventually the modular-based curriculum will accelerate the process to develop international medical students.

Although the above curriculum framework is clear and easy to follow, we should realize that the discussion of the research status from non-English speaking countries in this paper is not enough. In future research, we should 
collect as much information as possible from multiple sources (languages), especially from non-English-speaking countries, so as to further enrich and improve the curriculum framework of medical English.

\section{Acknowledgements}

We would like to thank Robert Tench for his proofreading of the text.

\section{Funding}

This research was funded by Higher Education Teaching Reform Project of National Ethnic Affairs Commission of PRC (Project Title: Research on the construction of modular course system for medical English from the perspective of ESP theory. Project No.: 19082. 国家民委高等教育教学改革（普通类）研究项目 “基于 ESP 理论视角医学英语模块化课程体系构建研究”, 课题编号: 19082), and National Foreign Language Teaching and Research Project in Higher education of SFLEP (Project Title: Research on the construction of medical academic English curriculum based on ESP theory. Project No.: 2019JL0001B. 外教社全国高校外语教学科 研项目“基于 ESP 理论视角医学学术英语课程建设研究”, 课题编号: 2019JL0001B).

\section{References}

An, Q. M., \& Zhang, K. C. (2020). College English curriculum reform based on the needs of medical students. Overseas English, 14(123).

Cao, X. P. (2016). Exploration of ESP teaching for postgraduates in medical school based on CBI concept. Continue Education Research, (8), 112.

Cui, X. P., Shi, C. Z., \& Xu, Y. B. (2013). Construction and practice of EGP+ESP in Shandong University. China University Teaching, (12), 60.

He, F. S. (2009). Course module construction and module combination. Journal of Vocational Education, (6), 155.

Hua, L., Zheng, Q., \& Zhao, G. J. (2014). On the practice of modular teaching theory in undergraduate quality education. Lantai World, (4), 1.

Long, Y. (2011). A study on the orientation of academic English courses in the improvement stage of college English. Foreign Language World, 146(5), 50.

Lv, G. (2008). Implication of Japan's EMP for medical English teaching at medical colleges and universities in China. Northwest Medical Education, 16(4), 743.

Ministry of Education of PRC. (2010). The national education reform and development of medium and long-term planning programs (2010-2020). Retrieved from http://www.moe.gov.cn/srcsite/A01/s7048/201007/t20100729_171904.html

Ministry of Education of PRC. (2018). On strengthening the collaboration between medicine and education to implement the Excellent Doctor Education Training Program 2.0. Retrieved from http://www.moe.gov.cn/srcsite/A08/moe_740/s7952/201810/t20181017_351901.html

Ministry of Education of PRC. (2018). Opinions on speeding up the construction of high-level undergraduate education and comprehensively improving the ability of talent cultivation. Retrieved from http://www.moe.gov.cn/srcsite/A08/s7056/201810/t20181017_351887.html

Ministry of Education of PRC. (2019). List of national institutions of higher learning in 2019. Retrieved from http://www.moe.gov.cn/jyb_xxgk/s5743/s5744/A03/201906/t20190617_386200.html

Ren, H. (2020, May 30). Interaction of professional connotation and language skills in medical English curriculum design. Paper presented at the Fourth National Conference on Medical English Teaching and Learning, China. Retrieved from Ding Talk Meeting. PPT.

Shen, W. W., Gu, Y., \& Shan, C. Y. (2014). English teaching reform in medical higher vocational colleges combined with medical culture. Education and Vocation, 816(32), 138.

Sun, M. Y. (1992). Dictionary of new disciplines in soft science of medicine. Beijing, China: World Book Publishing Corporation.

Wang, X. G. (2013). Construction of college English elective course in medical colleges. Journal of Inner Mongolia Normal University (Educational Science), 26(5), 107.

Wu, J. J., \& Feng, X. (2014). Research on the construction of the "multi-module integration" system of college 
English course. Journal of Fujian Medical University (social science edition), 15(1), 56.

Zhang, N. D., \& Liu, M. (2011). On the reform of English teaching in medical colleges. Educational Exploration, 245(11), 44.

Zhang, N. D., \& Wang, J. (2012). The enlightenment of EMP teaching in Tokyo Medical University on English teaching in medical colleges in China. Educational Exploration, 250(4), 158.

Zhang, X. H. (2014). College ESP curriculum mode and construction in the context of China (Doctoral dissertation, Shanghai International Studies University, Shanghai, China). Retrieved from https://kns.cnki.net/kns8/defaultresult/index

Zhao, G. W. (2013). Construction of English teaching system in medical universities in China (Doctoral dissertation, Shanghai International Studies University, Shanghai, China). Retrieved from https://kns.cnki.net/kns8/defaultresult/index

Zhao, J., \& Zhang, H. Z. (2014). Curricular reforms on ESP in the context of college entrance examination reforms. Journal of Hebei Normal University (educational science edition), 16(3), 130.

\section{Copyrights}

Copyright for this article is retained by the author(s), with first publication rights granted to the journal.

This is an open-access article distributed under the terms and conditions of the Creative Commons Attribution license (http://creativecommons.org/licenses/by/4.0/). 